\title{
Development of a Framework for Redesigning a Terminology Maintenance Process - Case Study in the Netherlands
}

\author{
Eva S. KLAPPE, ${ }^{\mathrm{a}, 1}$, Nicolette F. DE KEIZER ${ }^{\mathrm{a}}$ and Ronald CORNET ${ }^{\mathrm{a}}$ \\ ${ }^{a}$ Amsterdam UMC, University of Amsterdam, Department of Medical Informatics, Amsterdam \\ Public Health Research Institute, Amsterdam, Netherlands
}

\begin{abstract}
Structuring clinical data in electronic health records supports reuse of data to improve quality of care, reduce costs and perform research. This requires terminologies to assign terms from language used in a specific domain to medical concepts. Given the developing character of medical knowledge, these terminologies need continuous maintenance. Nonetheless, little is known about terminology maintenance processes. To specify the (re)design of a terminology maintenance process, we first merged and adapted two static theoretical frameworks that consisted of criteria relating to using a terminology, divided among relevant stakeholders. Following, we applied the framework to the healthcare terminology maintenance process in the Netherlands. We held interviews with relevant stakeholders and used the framework as checklist to identify missing criteria and bottlenecks. Saturation in interviews and fulfilment of the criteria indicated that all bottlenecks were discovered, therefore the framework was considered useful for redesigning a terminology maintenance process. Other countries could benefit from this framework as well to discover and resolve any unfulfilled maintenance criteria.
\end{abstract}

Keywords. Terminology maintenance, semantic interoperability, Electronic Health Records, EHR.

\section{Introduction}

Implementation of Electronic Health Records (EHRs) has been accompanied by the promise of increased patient safety, reduced medical errors, improved efficiency, reuse of healthcare data and reduced costs [1-4]. However, in order to realize these benefits, EHR systems need to be interoperable implying that data is unambiguous [1,2], while the often used free text, which is rich in details, can be ambiguous [3].

An approach to standardize the representation of clinical data and therewith improve interoperability is the use of (interface) terminologies $[1,5,6]$. Interface terminologies represent the language used in a particular domain and are used to describe lists of terms $[7,8]$. Interface terminologies facilitate the display of computer-stored patient information to human-understandable text, and structure clinical "free-text" expressions to more structured, machine interpretable expressions [9].

Given the developing nature of clinical knowledge these terminologies should be revised and maintained regularly $[1,5]$. Therefore, systematic terminology maintenance

${ }^{1}$ Corresponding Author, Eva S. Klappe. Amsterdam UMC, Department of Medical Informatics, Meibergdreef 15, 1105AZ Amsterdam, The Netherlands; E-mail: e.s.klappe@amsterdamumc.nl. 
is required $[10,11]$. While the need for an established design for maintenance processes has been acknowledged, few studies have been concerned with the actual organization of terminology maintenance processes [1, 12].

A framework by Raiez et al [10] highlights the importance of regularly updating terminologies by a maintenance organization. It should be possible to extend terminologies infinitely, using inactivation instead of removal of existing concepts. Available administrators should use an application or system for their maintenance process. Each new proposal should be documented and validated and performed in a standardized way. Another framework is the Dutch standard NEN 7522 "Maintenance of coding systems and other terminological systems" [13], which established seven activities relating to terminologies. These activities are assigned to a role: the user, authorizer, financer, distributor and three roles for maintaining the terminology, which are subdivided in a functional holder, a technical holder, and a general holder. The general holder surveys the other holders and distributors in their maintenance work. For instance, the functional holder focuses on the control of various versions of the terminology system and should propose changes for terminology terms based on demands from the user. A combination of NEN 7522 and the Raiez-framework could be a foundation for standardization of maintenance processes, but that has, to our knowledge, not been investigated.

In this study the goal was to (1) merge the frameworks into one, (2) apply the framework to an existing process to identify bottlenecks in the process and come up with solutions, and (3) check its validity by application.

\section{Methods}

First, we merged and adapted the two frameworks. The resulting framework concerned criteria relating to using a terminology, that were divided among the NEN 7522 roles. We did not include financers in examining the maintenance process, because they do not relate directly to the maintenance process, but to the provision of the maintenance system. Furthermore, only the Raiez-criteria specific for the maintenance process were assigned to the identified roles. The criteria that related to specific aspects of a terminology system itself (e.g. 'The codes that are assigned to concepts must be non-significant') were excluded.

Second, to test and validate the framework, we performed a case study. We applied the framework to the terminology maintenance process of two Dutch University Medical Centers. As in other countries, in the Netherlands a national organization, called Dutch Hospital Data (DHD), is responsible for the maintenance of the Diagnosis Thesaurus (DT), which is the terminology used in EHRs in most Dutch hospitals [14]. Healthcare providers make use of the DT to select the best-fitting diagnose (code) for their patients. We identified stakeholders and their roles in the process according to the framework. We recruited the stakeholders and asked them to recruit other stakeholders that were relevant according to the framework, i.e. snowball sampling. We held semi-structured interviews with the stakeholders until saturation was reached in finding bottlenecks (e.g., the time it takes to process change requests to the terminology is too long) in their terminology maintenance process, using the framework criteria as checklist. We discussed potential solutions for each missing item and we validated and translated these solutions into practical implications until no new implications arose in follow-up interviews (i.e. member checking [15]). In this way, we assessed the validity of the framework by 
monitoring whether saturation in the answers about missing criteria was reached and lead to fulfillment of all criteria.

\section{Results}

Figure 1 shows the 67 criteria in the merged framework per NEN 7522 role. In italic, the Raiez-criteria are shown.

Thirteen interviews were held with stakeholders, including clinicians, an employee of DHD and medical administrators, who were all assigned a role. Of the 67 criteria, 44 (65.7\%) were completely fulfilled, $16(23.9 \%)$ were partly fulfilled and $7(10.4 \%)$ were not fulfilled. Saturation was reached and in the second round of interviewing, all bottlenecks, solutions and practical implications were validated by relevant stakeholders. For instance, interviewees indicated that clinicians are currently not aware of the possibility of making change proposals or the way to do that (Figure 1, user ' $\mathrm{j}$ ', functional holder ' 1 '), which is why the DT is perceived incomplete and change proposals take long (Figure 1, functional holder ' $m$ ', ' $n$ '). An application to support the proposal process was not available, but was validated as solution to decrease response time and increase awareness (Figure 1, technical holder 'g', 'h', 'i', 'j').

\section{Discussion and conclusion}

To our knowledge, this study was the first to extend existing static theoretical frameworks that consisted of criteria relating to using a terminology, divided among stakeholders relevant in a terminology maintenance process, to an applicable framework checklist that can be used for the (re)design of a terminology maintenance process. We applied the framework and discovered that due to its "check listing" character, it was sufficiently easy to identify bottlenecks in the process, such as the need for increasing awareness and the use of applications for change proposals. Response time for change proposals could decrease and users will be aware of and perform more change proposals, leading to better maintained terminologies. This ultimately leads to improved user experience and data quality. Importance of creating awareness is also supported by Horsky [16] who mentioned that creating awareness results in better registration. The findings of this study also extend the need for a systematically arranged terminology maintenance process, as do [10], [11], and [17]. However, even if there is an established maintenance process to update terminologies in a way that they reach full coverage, studies show that other issues relating to terminology use should also be solved, e.g. a poor search-functionality could also be reason for perceived incompleteness $[18,19]$. A strength of our study is that it involved all relevant stakeholders and interviews were performed until saturation was reached, allowing us to assume that we captured all bottlenecks. One weakness is that we only examined one organization using the EHR (Epic). Nonetheless, as there are more hospitals that use Epic, even internationally, they might benefit from the results presented. Future research could use our steps and use the criteria of our framework to assess similar terminology maintenance processes. We also suggest establishing key performance indicators so practical solutions can be prioritized and executed based on their feasibility. It should be determined whether the executed implications improved the terminology maintenance process and whether this eventually leads to better data quality and reuse. 


\begin{tabular}{|c|c|c|c|}
\hline User & & Authorizer & $\begin{array}{l}\text { a) The authorizer must be known, and the authorizer must } \\
\text { acknowledge its role }\end{array}$ \\
\hline$\uparrow$ & \multicolumn{2}{|l|}{ a) The user must have sufficient knowledge of the terminology } & \multirow{2}{*}{$\begin{array}{l}\text { b) The authorizer must define the purpose of use, the collection } \\
\text { of elements and target audience for each terminology }\end{array}$} \\
\hline & \multicolumn{2}{|l|}{ b) The user must know the current version of the terminology } & \\
\hline & \multicolumn{2}{|l|}{ c) The user must know what version of the terminology he uses } & $\begin{array}{l}\text { c) The authorizer must contain a worked-out business plan for } \\
\text { terminology development and use }\end{array}$ \\
\hline & \multicolumn{2}{|l|}{$\begin{array}{l}\text { d) The user must register what versions he uses of the } \\
\text { terminology }\end{array}$} & $\begin{array}{l}\text { d) The authorizer must bear ultimate responsibility on decision- } \\
\text { making for proposals of changes and new terminology versions }\end{array}$ \\
\hline & \multicolumn{2}{|l|}{$\begin{array}{l}\text { e) The user is responsible for having the previous terminology } \\
\text { version(s) available when changing or analyzing data in the } \\
\text { terminology }\end{array}$} & $\begin{array}{l}\text { e) The authorizer must adhere to the purpose of the terminology } \\
\text { when making a decision }\end{array}$ \\
\hline & \multirow{2}{*}{\multicolumn{2}{|c|}{$\begin{array}{l}\text { f) The user must use and apply the terminology according to the } \\
\text { acknowledged business plan established by the authorizer. } \\
\text { These methods must explain correct terminology use }\end{array}$}} & $\begin{array}{l}\text { f) The authorizer assigns roles as proposed in this framework to } \\
\text { himself or other persons with regards to the terminology }\end{array}$ \\
\hline & \multirow{2}{*}{\multicolumn{2}{|c|}{$\begin{array}{l}\text { g) The user must use and apply the terminology according to its } \\
\text { acknowledged purpose }\end{array}$}} & $\begin{array}{l}\text { g) The authorizer is responsible for fully accommodating the } \\
\text { roles as proposed in the framework }\end{array}$ \\
\hline & & & \multirow{2}{*}{$\begin{array}{l}\text { h) The authorizer must give other roles the opportunity to } \\
\text { influence the decision-making with regards to proposals for } \\
\text { changes and new terminology versions }\end{array}$} \\
\hline & \multicolumn{2}{|l|}{ h) The user is not authorized to adjust the terminology } & \\
\hline & \multicolumn{2}{|l|}{$\begin{array}{l}\text { i) The user must inform the distributor about terminology use } \\
\text { and should be able to provide data about terminology use }\end{array}$} & $\begin{array}{l}\text { 1) Only qualified people are able to make changes } \\
\text { in terminology content }\end{array}$ \\
\hline & \multicolumn{2}{|l|}{$\begin{array}{l}\text { j) The user must be able to provide comments/change proposals } \\
\text { for terminology content to the f.h. }\end{array}$} & $\begin{array}{l}\text { j) There must be a 'change model' which defines all changes } \\
\text { that can occur in terminology content }\end{array}$ \\
\hline \multirow[t]{2}{*}{ Distributor } & a) The distributor must be known & & $\begin{array}{l}\text { k) For each change proposal, the consequences must be } \\
\text { determined and thereupon anticipated }\end{array}$ \\
\hline & $\begin{array}{l}\text { b) The distributor must distribute the terminology according } \\
\text { to the acknowledged process established by the holder }\end{array}$ & \multirow{5}{*}{ 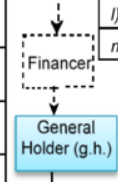 } & 1) Change proposals in terminology content must be validated \\
\hline & c) The distributor must make the current and previous & & m) Changes made in terminology content must be validated \\
\hline & terminology version available & & a) The g.h. must be known \\
\hline & $\begin{array}{l}\text { d) The distributor must notify all known users about the } \\
\text { availability of the current and previous terminology version }\end{array}$ & & b) The g.h. is responsible for terminology content \\
\hline & e) The distributor must notify all known users if there is a & & $\begin{array}{l}\text { c) The g.h. is responsible for operational activities with } \\
\text { regards to the terminology }\end{array}$ \\
\hline & $\begin{array}{l}\text { reason to change from the current terminology version to a } \\
\text { newer version }\end{array}$ & & $\begin{array}{l}\text { d) The g.h. oversees the distributing and technical and } \\
\text { functional terminology management according to an }\end{array}$ \\
\hline & $\begin{array}{l}\text { f) The distributor must allow users to contact them and } \\
\text { obtain the terminology }\end{array}$ & & $\begin{array}{l}\text { acknowledged process that was established by the } \\
\text { holder themselves }\end{array}$ \\
\hline & $\begin{array}{l}\text { g) The distributor is responsible for predetermining the } \\
\text { delivery time of the terminology and must ensure that the } \\
\text { predetermined time frame is achieved when the terminology }\end{array}$ & & $\begin{array}{l}\text { e) The g.h. is responsible for the process design on how to } \\
\text { provide the users with support and terminology-specific } \\
\text { information }\end{array}$ \\
\hline & is requested by (new) users & & f) The g.h. must monitor terminology use \\
\hline & $\begin{array}{l}\text { h) The distributor is responsible for making the prices } \\
\text { available for terminology use and handle the financial } \\
\text { settlement }\end{array}$ & & $\begin{array}{l}\text { g) The g.h. must give users the opportunity to influence } \\
\text { decision-making with regards to terminology maintenance }\end{array}$ \\
\hline & $\begin{array}{l}\text { i) New terminology versions must be provided with a unique } \\
\text { identification number and publication date }\end{array}$ & & $\begin{array}{l}\text { h) The g.h. must decide on the method for distribution of the } \\
\text { terminology, inform the distributor about this method and } \\
\text { enforce the distributor to perform accordingly }\end{array}$ \\
\hline & $\begin{array}{l}\text { j) On average, a new terminology version should be } \\
\text { launched twice per year }\end{array}$ & & a) The f.h. must be known \\
\hline & & $\begin{array}{l}\text { Functional } \\
\text { Holder (f.h.) }\end{array}$ & b) The f.h. must work on behalf of the authorizer \\
\hline & & & c) The f.h. must manage terminology content and \\
\hline & a) The t.h. must be known & & \\
\hline & $\begin{array}{l}\text { b) The t.h. must have the terminology available in a technical } \\
\text { management environment }\end{array}$ & & $\begin{array}{l}\text { d)The f.h. must apply a best practice method for users with } \\
\text { regards to terminology maintenance and general support }\end{array}$ \\
\hline & c) The th. must be able to subject the terminology to version ce & control & $\begin{array}{l}\text { e) The f.h. is in control of version control and aligns this with } \\
\text { t.h. }\end{array}$ \\
\hline & d) The t.h. must have the historical terminology versions availa & able & f) The f.h. must propose changes to the terminology based \\
\hline & $\begin{array}{l}\text { e) There must be a secured application for the terminology mai } \\
\text { process that supports managing different terminology versions }\end{array}$ & $\begin{array}{l}\text { aintenance } \\
s\end{array}$ & Orine users \\
\hline & $\begin{array}{l}\text { f) There must be a secured application for the terminology mair } \\
\text { process that supports editing new versions of the terminology } f\end{array}$ & $\begin{array}{l}\text { intenance } \\
\text { for }\end{array}$ & $\begin{array}{l}\text { g) The f.h. is responsible for assigning the maintenance } \\
\text { team, who are responsible for the organization of } \\
\text { terminology maintenance }\end{array}$ \\
\hline & \begin{tabular}{|l} 
distribution \\
g) There must be a secured application for the terminology
\end{tabular} & & $\begin{array}{l}\text { h) Different relevant disciplines must be involved within the } \\
\text { maintenance team }\end{array}$ \\
\hline & $\begin{array}{l}\text { maintenance process that supports collecting change proposa } \\
\text { regards to the content of the terminology }\end{array}$ & & $\begin{array}{l}\text { i) Change proposals with regards to the terminology must be } \\
\text { standardized }\end{array}$ \\
\hline & $\begin{array}{l}\text { h) There must be a secured application for the terminology mai } \\
\text { process that contains a module to enable the consensus proce } \\
\text { change proposals }\end{array}$ & $\begin{array}{l}\text { aintenance } \\
\text { ess for }\end{array}$ & $\begin{array}{l}\text { j) Change proposals with regards to the terminology must be } \\
\text { documented }\end{array}$ \\
\hline & i) There must be a secured application for the terminology mair & intenance & k) Documentation must be structured and standardized \\
\hline & $\begin{array}{l}\text { process that supports automatic validation controls for change } \\
\text { proposals }\end{array}$ & & 1) The maintenance team must be easily accessible \\
\hline & j) There must be a secured application for the terminology mair & & $\begin{array}{l}\text { m) The response time of the maintenance team on } \\
\text { proposals and questions must be short }\end{array}$ \\
\hline & & & $\begin{array}{l}\text { n) Change proposals with regards to the terminology must } \\
\text { be processed within a predetermined time period }\end{array}$ \\
\hline & & & $\begin{array}{l}\text { o) The f.h. must use a supporting system for their } \\
\text { terminology maintenance process }\end{array}$ \\
\hline & & & $\begin{array}{l}\text { p) Changes made in terminology content must be } \\
\text { documented }\end{array}$ \\
\hline
\end{tabular}

Figure 1. The merged framework. In italic the criteria from the Raiez-framework are shown, that were divided among the NEN 7522 roles. 


\section{References}

[1] Park H, Hardiker N. Clinical terminologies: a solution for semantic interoperability. J Korean Soc Med Inform. 2009;15(1):1-11.

[2] Hwang KH, Chung K-I, Chung M, Choi D. Review of semantically interoperable electronic health records for ubiquitous healthcare. Healthc Inform Res. 2010;16(1):1-5.

[3] de Quirós FGB, Otero C, Luna D. Terminology Services: Standard Terminologies to Control Health Vocabulary. Yearb Med Inform. 2018;227:33.

[4] Andrews JC, Bogliatto F, Lawson HW, Bornstein J. Speaking the same language: using standardized terminology. J Low Genit Tract Dis. 2016.

[5] Rosenbloom ST, Miller RA, Johnson KB, Elkin PL, Brown SH. A model for evaluating interface terminologies. J Am Med Inform Assn. 2008;15(1):65-76.

[6] Wade G, Rosenbloom ST. The impact of SNOMED CT revisions on a mapped interface terminology: terminology development and implementation issues. J Biomed Inform. 2009;42(3):490-3.

[7] Schulz S, Rodrigues JM, Rector A, Chute CG. Interface Terminologies, Reference Terminologies and Aggregation Terminologies: A Strategy for Better Integration. Stud Health Technol Inform. 2017;245:940-4.

[8] Rosenbloom ST, Miller RA, Johnson KB, Elkin PL, Brown SH. Interface terminologies: facilitating direct entry of clinical data into electronic health record systems. J Am Med Inform Assn. 2006;13(3):277-88.

[9] Kim TY, Coenen A, Hardiker N. A quality improvement model for healthcare terminologies. J Biomed Inform. 2010;43(6):1036-43.

[10] Raiez F, Arts D, Cornet R. Terminological system maintenance: a procedures framework and an exploration of current practice. Stud Health Technol Inform. 2005;116:701.

[11] Bakhshi-Raiez F, Cornet R, de Keizer NF. Development and application of a framework for maintenance of medical terminological systems. J Am Med Inform Assoc. 2008;15(5):687-700.

[12] Aryel RM, Cai J, Chueh HC, Barnett GO, editors. Maintaining the integrity of a Web-based medical vocabulary glossary. AMIA Annu Symp Proc; 1997: American Medical Informatics Association.

[13] NIN. NEN 7522 - hanteren van code- en andere terminologiestelsels. Delft: Nederlands NormalisatieInstituut; 2010.

[14] Dutch Hospital Data. Diagnosethesaurus. 2020. Available at: https://www.dhd.nl/productendiensten/diagnosethesaurus/Paginas/Diagnosethesaurus.aspx. Accessed 17 December 2020.

[15] Creswell JW, Miller DL. Determining validity in qualitative inquiry. Theory into practice. 2000;39(3):124-30.

[16] Horsky J, Drucker EA, Ramelson HZ, editors. Accuracy and Completeness of Clinical Coding Using ICD-10 for Ambulatory Visits. AMIA Annu Symp Proc; 2017.

[17] Wade G, Rosenbloom ST, editors. Experiences mapping a legacy interface terminology to SNOMED CT. BMC Med Inform Decis; 2008: BioMed Central.

[18] Cimino JJ, Patel VL, Kushniruk AW. Studying the human-computer-terminology interface. J Am Med Inform Assoc. 2001;8(2):163-73.

[19] Klappe ES, de Keizer NF, Cornet R. Factors Influencing Problem List Use in Electronic Health Records-Application of the Unified Theory of Acceptance and Use of Technology. Appl Clin Inform. 2020;11(03):415-26. 